\title{
LA DISCRIMINACIÓN POR RAZONES GREMIALES COMO DIFERENCIA FUNCIONAL Y SU IMPACTO EN EL SISTEMA JURÍDICO SINDICAL ARGENTINO
}

\section{Leonardo J. Ambesi}

\author{
Departamento de Derecho del Trabajo, Facultad de Derecho, Universidad Austral \\ lambesi@austral.edu.ar
}

Recibido: 07/09/2021

Aceptado: 10/11/2021

\section{Resumen}

La Ley 23592 sanciona con la nulidad, entre otros supuestos, los actos discriminatorios realizados por motivos de opinión gremial. A partir de su consolidación jurisprudencial, se ha interpretado con carácter amplio el alcance de esta norma, incluyendo las distintas manifestaciones de la actividad sindical así como los diferentes sujetos que las llevan a cabo.

En la práctica, ello ha significado la prevalencia del ordenamiento antidiscriminatorio por sobre el de la Ley 23551 de Asociaciones Sindicales, elaborándose un sistema particular que impone una vía procesal y pautas probatorias propias que, en caso de despido, derivan en la reinstalación del afectado a su puesto de trabajo. Como resultado de esta tendencia, en el máximo nivel judicial se ha intentado deslindar los campos de aplicación de ambas normas, así como la defensa que el empleador puede oponer en cada caso, sin que al momento se haya alcanzado este objetivo en plenitud.

En el marco antes citado, el presente trabajo pretende analizar el problema con apoyo en las nociones básicas de la teoría de los sistemas complejos de Luhmann, a fin de poner en evidencia la naturaleza funcional de un asunto, que ha derivado, a través de sucesivas diferenciaciones, en la creación de un régimen autónomo de protección contra la discriminación sindical en su sentido más amplio.

Palabras clave: sistema, discriminación, opinión, actividad, sindical, función. 


\title{
Discrimination Based on Union Activity as a Functional Difference and its Impact on the Argentine Union Legal System
}

\begin{abstract}
Law 23592 nullifies discriminatory acts based on reasons of union support or opinion. Since its jurisprudential consolidation, the scope of this rule has been interpreted broadly, including extensive manifestations of union activity as well as the different participants that carry them out. In the practice, this results in the prevalence of the Anti-discrimination Law 23592 over the Trade Union Law 23551, developing a peculiar system with its own procedure and rules of evidence that, in the event of dismissal, may lead to the reinstatement of the affected person into the workplace.

As result of this court trend, there have been attempts at the highest judicial level to establish the boundaries of both rules, as well as the defenses that the employer can oppose in each case, purpose that at the moment hasn't been fully achieved.

The present work attempts to analyze the problem with the support of the basic notions of Luhmann's theory of complex systems, in order to highlight the functional nature of the issue, which has derived in the creation of an autonomous system of protection against union discrimination in its broadest sense.
\end{abstract}

Key words: system, discrimination, opinion, activity, union, function.

\section{Introducción}

Hace una década, la Corte Suprema de Justicia de la Nación determinó la plena vigencia de la Ley 23592 antidiscriminatoria en el ámbito de las relaciones laborales. La confirmación de la tendencia jurisprudencial favorable que se había desarrollado en este sentido consolidó la existencia de reclamos en los que la alegación de un obrar discriminatorio por razones sindicales, esencialmente en casos de despido, tiene allí su argumento principal o concurrente. Esta particularidad contiene un doble componente: el primero, de raíz subjetiva, al ser invocada por quienes -debido a variadas circunstancias- no se encuentran expresamente tutelados por la Ley 23551 de asociaciones sindicales; el segundo, de índole objetiva, al recurrirse a la noción de "opinión gremial" contenida en la norma citada al inicio, que se ha expandido hasta comprender distintas situaciones de actividad sindical.

Dicha proyección de la Ley 23592 ha dado lugar a múltiples debates. Desde los efectos retroactivos que derivan de la calificación de nulidad atribuida a la conducta discriminatoria, con el lógico regreso a la situación anterior (para el despido, ello implica, como principio, la reinstalación del trabajador), pasando por el motivo imputado (aquí la opinión o actividad de naturaleza gremial), 
siguiendo por la exigencia que se le requiere al pretensor para acreditar la existencia de su actividad y el alcance del acto censurado (indicios verosímiles) hasta llegar al modo de asignar y apreciar la prueba que pueden producir las partes (carga probatoria).

Junto a estas temáticas, sin embargo, aparece otra que no ha recibido idéntica difusión, como es de la funcionalidad que presenta el citado conglomerado jurídico-jurisprudencial, que ha provocado, entre otras consecuencias, la pérdida de protagonismo en el tema de la Ley 23551, que en varias de estas controversias ha quedado subordinada como simple vehículo procesal de la norma anterior.

Para destacar la importancia que posee esta situación, se ha estimado conveniente apelar a la metodología descriptiva desarrollada por Niklas Luhmann respecto a los sistemas complejos, especialmente los jurídicos. La adopción de algunas de las herramientas conceptuales planteadas por Luhmann permite una mejor comprensión de las dificultades internas que se evidencian en un sistema concreto ante el despliegue de otro que ofrece un mayor nivel de efectividad frente a las aspiraciones de los involucrados.

Como paso previo a transitar el recorrido jurisprudencial que ha seguido el proceso en estudio, el camino propuesto obliga a detenerse en una teoría que, irónicamente, hace de la diferencia su nudo central, la cual se utilizará aquí para comprender el ascenso de un sistema jurídico que justamente sanciona la distinción peyorativa, asumiéndola como discriminación.

Corresponde efectuarle al lector dos advertencias antes de emprender esta marcha. En la primera de ellas se advierte que no se trata aquí de asumir una determinada postura antropológica del pensamiento luhmanniano (la que ha merecido serías y fundadas críticas), tampoco aceptar sin reservas todas sus conclusiones vinculadas al sistema jurídico (que también ha tenido sus objeciones, algunas de las cuales se mencionarán a lo largo de este trabajo), sino de emplear algunos de sus lineamientos básicos para describir lo sucedido con ambos sistemas jurídicos. ${ }^{1}$ En segundo lugar, se previene que, salvo en lo inevitable, las referencias constitucionales y/o de otros niveles normativos serán mínimas. En esta aproximación, lo que importa es la funcionalidad sistémica y cómo, desde ella, se pueden alumbrar los fenómenos jurídicos en juego. Se apartan, sin des-

1 Sobre las críticas a este aspecto, ver Miranda Rebeco (2012). Sin embargo, para contradecir esta atribución al pensamiento del autor, podemos citar sus clases sobre el amor; ver Luhmann (2012). A juicio de este humilde lector, a pesar de estar en clave sistémica, su ocupación del tema ya lo redime de su potencial ahumanidad. 
merecerlos por cierto, otros acercamientos a la cuestión planteada, sea desde el derecho constitucional, el derecho internacional de los derechos humanos, la perspectiva hermenéutica o la teoría de la decisión, por citar algunos de ellos. Aquí interesa observar el diseño de cada conjunto normativo en el tema propuesto, para luego detenerse en el proceso de expansión indicado al inicio.

\section{Los sistemas sociales y jurídicos complejos}

A la hora de ingresar en las concepciones de Luhmann sobre los sistemas hay que recordar que, para el citado autor, el carácter complejo de la sociedad moderna proviene de haber superado los parámetros anteriores de la organización jerárquica y de la circulación centro/periferia para sustentarse en la denominada "diferenciación funcional" que, a su criterio, es lo que tiene primacía (Luhmann, 2007b, pp. 118 y 763). El constructivismo se manifiesta en este pensamiento, por ello, se le otorga significación al concepto "función", alejado de la idea de "sustancia", y más bien asentado en el terreno de la "capacidad" para ordenar posibilidades, algo que ya realiza el ser humano como sistema individual (Luhmann, 2010, pp. 147-149).

Esta apelación a la función como aptitud ordenativa se revela en el conocido paradigma sobre el que se elaboró esta teoría, conformado por la diferencia entre "sistema" y "entorno". En sus palabras, "los sistemas se constituyen y se mantienen mediante la creación y la conservación de la diferencia con el entorno, y utilizan sus límites para regular dicha diferencia” (Luhmann, 1998b, p. 40).

La mentada frontera, de carácter externo, no impide la existencia de relaciones entre dichos contextos; por el contrario, entre ambos se desarrolla un proceso de intercambio de comunicaciones que varía en cada caso. Lo destacable es que el sistema social no mantiene una relación jerárquica con el entorno. Una vez recibida la comunicación, es procesada en su interior de manera independiente. En esto, los sistemas se autoorganizan, crean sus propias estructuras de conexión; son autónomos y, a la vez, autopoiéticos, es decir, producen las operaciones que son necesarias para producir más operaciones, sirviéndose para ello de su propia red (Luhmann, 2007a, p. 118). ${ }^{2}$

La autonomía supone la existencia de un sistema operativamente cerrado.

2 Es conocida la influencia en el tema de la autopoiesis de Maturana y Varela, aunque Luhmann y el primero de los autores aludidos no dejaron de señalar sus discrepancias en el empleo de la acepción. Ver al respecto Nafarrate (2009). 
No resulta posible para Luhmann la noción de una autonomía relativa: los sistemas producen sus propios procedimientos, operaciones y estructuras bajo un determinado código que los define. En general, esta codificación es única y alude a un par binario de valores contrapuestos (para el sistema jurídico, "conforme a derecho/no conforme a derecho"), aunque en algunos casos (como la política o la economía) ha admitido la presencia de medios primarios y secundarios, al entenderlos como resultado de la evolución social (Baxter, 2013).

Ahora bien, así como se manifiesta el sistema hacia el exterior mediante su diferencia con el entorno, en su aspecto interno se observa también la aparición de diferenciaciones, que replican en el interior aquella distinción primera, provocando un aumento de la complejidad del sistema, pero permitiendo al mismo tiempo nuevas formas de reducción de esa misma complejidad. Cada unidad efectúa selecciones de posibilidades a su nivel y repite en sí misma la formación del sistema global; en palabras de Luhmann (1998b), "multiplica su propia realidad” (p. 184). La construcción de la diferencia se encuentra ligada a la de la identidad: desde su distinción con el entorno, un observador puede visualizar los rasgos que confieren al sistema su unidad como tal, pero ello es algo que el propio sistema también percibe y sobre lo cual reflexiona para sí (Corsi et al., 2006, pp. 118-121). ${ }^{3}$

La reducción de la complejidad es otro de los temas fundamentales. En las sociedades modernas, los sistemas sociales se ocupan de gestionar esa tarea mediante la faena de reducir lo complejo creando algo más complejo. Luhmann, maestro de paradojas, pone de relieve en este esquema uno de los dilemas que deben resolver los sistemas: el que designa como "doble contingencia", es decir, "aquello que puede ser como es (fue, será), pero puede ser de otro modo. El concepto designa, por lo tanto, lo dado (experimentado, esperado, pensado, imaginado) a la luz de un posible estado diferente" (Luhmann, 1998b, pp. 115116). Para superar la doble contingencia, hay que trabajar en términos de expectativas -favorables y/o desfavorables-, de riesgos y, sobre todo, de selecciones, articuladas por los sistemas como mecanismo de gestión de la incertidumbre.

En el derecho, la doble contingencia obliga a pensar alternativas tanto a quienes comparecen en un litigio como a quienes deben resolverlo, porque la solución dentro de los distintos mecanismos internos del sistema admite la eventualidad de que exprese en uno u otro sentido. Esto no supone un proce-

3 No es casual que los autores -en particular Elena Esposito-, al relevar el vocablo, tomaran en cuenta la entrada del estudio sobre los sistemas sociales, realizado por Luhmann (1990), titulado "Identität - was oder wie" (p. 121). 
dimiento anárquico, sino más bien una red jurídicamente ordenada de otras posibilidades (Luhmann, 2019, p. 142).

Por eso, la doble contingencia remite al par "confianza/desconfianza" como factor de tolerancia a esa incertidumbre que se origina en las relaciones con el sistema. Este es un problema de reducción de complejidad y, para ello, el sistema "[...] sustituye la certeza externa por la certeza interna, y al hacerlo eleva la tolerancia de la incertidumbre en las relaciones externas" (Luhmann, 2005, p. 45).

Hasta ahora se han reseñado algunos conceptos elementales de la teoría convocada: "sistema y entorno", "diferenciación funcional", "complejidad", "doble contingencia” y "confianza”. El interrogante que sigue a esto es cómo reacciona un sistema determinado frente a un cambio en el entorno. La respuesta de Luhmann (1998b, pp. 173-176, 183) consiste en advertir que los cambios en el entorno provocan adaptaciones al sistema e implican cambios en el entorno de otros sistemas; al mismo tiempo, se abren nuevas formaciones de sistema, con renovadas diferencias y limitaciones. En estos movimientos, también hay lugar para la llamada "interpenetración", esto es, "[...] cuando ambos sistemas se posibilitan mutuamente aportar al otro su propia complejidad preconstituida" (p. 202).

La parte final (y no menos importante) de este segmento se dedica a completar lo dicho sobre la complejidad de los sistemas jurídicos complejos. Para el catedrático de Bielefeld, todos son conceptos que remiten a la reducción de complejidad por conducto de la doble contingencia. En este punto, el derecho deberá operar también en una paradoja ("conforme a derecho"/"no conforme a derecho") en la que la complejidad se reduce a partir de la programación de una fórmula (v.gr., la "justicia" u otra) que no necesita fundamentarse por sí misma y que se hace relevante para todas las decisiones que se adoptan al respecto (Luhmann, 2005, pp. 284-285).

Como se anticipó, el esfuerzo del sistema jurídico se concentra en gestionar las incertidumbres externas mediante el grado de confianza que genera desde la esfera interna. Por ello,

la estructura de un sistema puede aumentar la tolerancia a la incertidumbre por la manera en la que clasifica las certidumbres; es más, solo alcanzará una complejidad sistémica típicamente superior si prevé más certidumbres y, al mismo tiempo, más incertidumbres. De ahí que la certidumbre no pueda ser concebida solo como lo contrario de la incertidumbre, sino también como una incertidumbre estructurada. (Luhmann, 2019, p. 135) 
La descripción precedente, vinculada al cariz autopoiético del sistema jurídico, transmite otro interrogante: ¿qué sucede cuando el sistema ya no puede resolver los problemas que produce? La respuesta es contundente: estos "[...] tienen que ser transferidos al sistema que está mejor preparado y especializado para resolverlos" (Luhmann, 1998a, p. 93).

Ahora, con la asistencia de estos elementos conceptuales y metodológicos de nuestra "caja de herramientas", ha llegado el momento de avanzar en la consideración de lo sucedido en el tema planteado.

\section{La discriminación y el sistema de la ley de asociaciones sindicales}

En una rápida mirada, puede notarse que el modelo establecido en 1988 por la Ley 23551, tomado en su versión original, se asemeja bastante a las nociones de "sistema autónomo", "autorreferente" y "autopoiético" de Luhmann. Contiene un código binario principal, como es el de "libertad sindical/no libertad sindical”, en los términos en los que el propio sistema decide (ver su título preliminar, artículos 1 a 3), del cual se desprende un conjunto de subcódigos, operaciones, procedimientos y estructuras que, a partir de esa matriz, se despliegan para absorber las cargas de expectativas que allí depositan los interesados. Estos grados de confianza se administran a partir de sucesivas diferenciaciones internas. De esta manera, la Ley 23551 replica en su interior variadas diferenciaciones funcionales. Comienza por la más básica, "trabajador/afiliado", pasando luego a la de "afiliado/delegado" así como a la de "delegado/autoridad sindical”. En materia de representación, la dupla es bien evidente al asignarles determinados derechos a los sindicatos, según sean reconocidos como "más representativos" frente a aquellos que no lo son, denominando a los primeros "con personería gremial" y a los otros "inscriptos" (artículos 23, 25-28 y 31). Los trabajadores, volviendo a los primeros niveles distintivos, tienen en este ordenamiento un conjunto de derechos que se les reconoce por su condición de tales, entre los que se cuentan los de "reunirse y desarrollar actividades sindicales" y "peticionar ante las autoridades y empleadores" (artículo 4, inciso c).

La técnica no es ajena al derecho, y menos al derecho colectivo del trabajo, que bien puede verse como un producto de recurrentes desgajamientos desde las ramas jurídicas públicas y privadas, y particularmente desde el propio derecho individual laboral (Simon, 2012a, p. 4).

Es curioso, pero la impronta organicista de la ley, que remite prácticamente la totalidad de la vida gremial al sindicato, ha dejado en este artículo, junto a 
otras garantías (constituir libremente entidades, afiliarse, no afiliarse, desafiliarse, participar en la vida interna de las organizaciones) un espacio a la acción y a la expresión que no se encuentra mediado y, por lo tanto, resguarda la posibilidad del activismo.

¿Qué sucede con la discriminación? El sistema de la Ley 23551 contiene una norma relativa al tema, al establecer en su artículo 7:

Las asociaciones sindicales no podrán establecer diferencias por razones ideológicas, políticas, sociales, de credo, nacionalidad, raza o sexo, debiendo abstenerse de dar un trato discriminatorio a sus afiliados. Lo dispuesto regirá también respecto de la relación entre una asociación de grado superior y otra de grado inferior.

El dispositivo, además de su relevancia, posee una estructura que opera a distintos niveles; comprende las situaciones de tratamiento organización/individuo, por una parte, y, por otra, en forma convergente las de organización/ organización. Sin embargo, se observa una carencia evidente, como es la posible conducta y consecuente tutela que se tenga respecto a los trabajadores no afiliados. Por supuesto, tampoco se contemplan otras discriminaciones que se produzcan fuera del continente plasmado por la estructura sindical.

Una explicación del tema la encontramos en López (1998, p. 122), para quien la norma en cuestión funge como una derivación en clave de igualdad de la garantía constitucional de "organización sindical libre y democrática" del artículo 14 bis de la Constitución Nacional (CN), esto es, una inserción del principio de igualdad destinado a todo los habitantes del país dentro de la entidad gremial. ${ }^{4}$ Esta proyección no es exclusiva del régimen sindical, por cuanto también se predicaba similar fundamento para el sistema de la Ley 20744 de Contrato de Trabajo, que ya contenía expresas disposiciones que le prohibían al empleador la discriminación, entre otras causales por motivaciones gremiales, y le ordenaban la dispensa de un trato igualitario a los trabajadores (artículos 17 y 81; López et al., 1987, p. 227).

Más allá de lo expuesto, hay que recordar que la ley cuenta con un procedimiento, como es el del amparo sindical, que legitima a todo trabajador o asociación sindical que "[...] fuere impedido u obstaculizado en el ejercicio regular de los derechos de la libertad sindical garantizados por la presente ley [...]", para "[...] recabar el amparo de estos derechos ante el tribunal judicial competente

4 La versión actualizada por Julio C. Simon (2012, pp. 222-223) se mantiene sin cambios en este punto. 
[...] a fin de que éste disponga, si correspondiere, el cese inmediato del comportamiento antisindical" (artículo 47).

La textura del articulado refuerza, sin dudas, el sentido autopoiético que se viene afirmando. Los derechos comprometidos deben obedecer a un "ejercicio regular" y ser de la "libertad sindical" definida y comprendida por la ley. A su vez, el "cese inmediato" refiere a un detenimiento certero de una conducta u omisión que merezca ser calificada de "antisindical", lo cual permite contener en su interior los comportamientos discriminatorios por razones gremiales, cualquiera sea el sujeto que los lleve a cabo.

La doctrina contemporánea interpretó la presencia de esta vía específica de manera integrada y, lo que es más interesante para el presente análisis, desde una perspectiva sistémica. Así, para Rodríguez Mancini (1992)

\begin{abstract}
[...] entre la acción del artículo 47 y el resto de los dispositivos con los cuales se configura el sistema de organización sindical y de protección de los derechos de la libertad sindical se puede establecer la misma relación jurídico procesal que la que existe entre la acción de amparo [...] y las acciones comunes que son resueltas por las vías ordinarias ante los jueces competentes [...] porque es coherente con el sistema y la naturaleza de una acción de esta especie, a que no existan otros procedimientos propios para tramitar la cuestión. (p. 299)
\end{abstract}

Ahora bien, esta visión desde el "sistema" no le había impedido al citado autor reflejar, a poco tiempo de vigencia de la ley sindical, algunas de las cuestiones controvertidas que su contenido presentaba -a su criterio- desde el punto de vista constitucional. En dicha aproximación, Rodríguez Mancini acompañó su trabajo con un ejemplar de la presentación del informe realizado por Nicolás Valticos, enviado por la Organización Internacional del Trabajo (OIT) en mayo de 1984 a la República Argentina con motivo de la elaboración de una nueva ley en la materia. Si bien no se trató del texto que estamos analizando, no está de más señalar que uno de los tópicos en los que hizo hincapié el experto era el de asegurar "[...] una protección más eficaz contra los actos de discriminación antisindical a todos los trabajadores" (Rodríguez Mancini, 1988, p. 1217). El tema de la discriminación del trabajador en la afiliación, por otra parte, ya había sido considerado en la doctrina (Fernández Madrid, 1985).

Dichos antecedentes acreditan que la problemática referida al alcance del amparo sindical y su eventual conexión con las conductas discriminatorias ya tenía su tiempo y habitaba en lo que podríamos afirmar el "entorno" del sistema. Otra voz poderosa como la de Vázquez Vialard (1989), que toma la idea 
desarrollada por J. López (1987) sobre la extensión de la protección del despido arbitrario, reflexionó por esa época a partir de la potencial eficacia que tendría el amparo sindical como tutela sindical genérica. Apeló para ello a otro dispositivo del sistema jurídico sindical que sanciona como práctica desleal, imputable a los empleadores o a las asociaciones que los representen, la conducta tendiente a "practicar trato discriminatorio, cualquiera sea su forma, en razón del ejercicio de los derechos sindicales tutelados por este régimen" (artículo 53, inciso j). Según el jurista, dado que la ley les garantiza a los trabajadores reunirse y desarrollar actividades sindicales, ante una medida adoptada por el empleador para impedir el goce de tales derechos, se permitiría el inicio de una acción dirigida a que el juez disponga el cese de dichas obstrucciones, con base en este artículo; así, "el trabajador afectado [...] previa comprobación en juicio contencioso, tiene derecho a que el juez disponga el cese inmediato y la 'reinstalación' de las condiciones de trabajo anteriormente vigentes (statu quo ante)" (Vázquez Vialard, 1989, p. 11).

En suma, el diseño de la Ley 23551 de asociaciones sindicales, desde su versión original, contiene en su interior una serie de diferenciaciones funcionales producidas por su propio código de lo que entiende el sistema por "libertad sindical", que se replica de manera constante brindándole la identidad (y unidad) que necesita para continuar operando. Esta identidad hace que las dos acciones antes descriptas, amparo sindical y querella por práctica desleal, más que como procedimientos se erijan como validadores del propio sistema. En otras palabras, no puede haber legitimación activa para el amparo sindical por una eventual conducta discriminatoria que no sea como consecuencia del "ejercicio regular" de los derechos de libertad sindical protegidos por la ley, ni práctica desleal que no se vincule con la discriminación en el ejercicio de aquellos derechos sindicales que no sean los "tutelados por este régimen". La autoproducción luhmanniana se muestra así en todo su esplendor.

\section{La entrada en vigencia de la ley antidiscriminatoria en el ámbito laboral y sus consecuencias para la discriminación por motivos gremiales}

Desde la perspectiva del sistema cerrado, la valoración formulada respecto a la Ley 23592, destinada a sancionar comportamientos discriminatorios, no suscitó mayor controversia. Es probable que, al ser una norma coetánea de la ley sindical (se publicó en el Boletín Oficial el 05/09/1988, cinco meses después de la Ley 23551), haya sido considerada desde el inicio como un régimen dirigi- 
do específicamente a un conjunto de fenómenos poco observados en el sistema sindical. Su lenguaje parece confirmarlo:

Art. $1^{\circ}$.- Quien arbitrariamente impida, obstruya, restrinja o de algún modo menoscabe el pleno ejercicio sobre bases igualitarias de los derechos y garantías fundamentales reconocidos en la Constitución Nacional, será obligado, a pedido del damnificado, a dejar sin efecto el acto discriminatorio o cesar en su realización y a reparar el daño moral y material ocasionados.

A los efectos del presente artículo se considerarán particularmente los actos u omisiones discriminatorios determinados por motivos tales como raza, religión, nacionalidad, ideología, opinión política o gremial, sexo, posición económica, condición social o caracteres físicos.

Como puede observarse, se habla de "bases igualitarias", de "motivos" y, fundamentalmente, de "opinión" en clave política o sindical, un aspecto este último que se desgrana luego en el combate a los tópicos discriminatorios más universales. ${ }^{5}$

Finalmente, si bien la reforma constitucional de 1994 incorporó la figura del amparo (artículo 43), situó a nivel constitucional un conjunto de convenciones, pactos y tratados internacionales sobre derechos humanos, en los cuales se menciona el Convenio 87 de la OIT sobre Libertad Sindical, y fortaleció la idea tendiente a considerar a los demás convenios de esa organización como fuente supralegal (entre ellos, el Convenio 111 sobre la discriminación en el empleo y la ocupación, ratificado por Argentina mediante Ley 11677 de 1968), lo cual no aparentaba una amenaza concreta a los postulados congénitos de la Ley 23551. A modo de ejemplo, merece citarse una sentencia pionera de la Cámara Nacional de Apelaciones del Trabajo en esta época, en la que el elemento de "opinión" (de tipo política) fue excluyente para resolver la nulidad de un despido. ${ }^{6}$

La presión del "entorno", sin embargo, vendría con el giro neoconstitucional de la jurisprudencia.

5 Se contempla especialmente la elevación del máximo previsto en la escala penal cuando la actividad sea cometida por persecución u odio a una raza, religión o nacionalidad, con el objeto de destruir todo o parte de un grupo por tales razones, incluyendo un tipo penal para quienes participen de una organización o realicen propaganda de superioridad sobre tales aspectos, o incitaren a la persecución y al odio por causa de ello (artículos 2 y 3 ).

6 Cámara Nacional de Apelaciones del Trabajo, Sala X, 29/06/2001, Stafforini, Marcelo c/Estado Nacional. 
En la crítica que le formulan Van der Kerchove y Ost (1988) al paradigma de Luhmann se advierte, entre otras observaciones, el reproche dedicado a la pretensión de completa autonomía del sistema jurídico. En sus palabras, aun cuando los sistemas -bajo su propio control- posean la capacidad de modificar las informaciones que tratan e incluso sus reglas de funcionamiento, tal cualidad es parcial, en tanto ello supone un salto cualitativo hacia una mayor complejidad:

Dicho de otro modo, los únicos cambios que afectan a la organización misma -y no únicamente a los diferentes estados del sistema, que no son otra cosa que las fases de un programa constante- deben producirse desde el exterior del sistema. (Van der Kerchove y Ost, 1988, pp. 139-140)

Aquí, esa exterioridad tuvo como punto de partida la entrada del derecho del trabajo argentino en la corriente del neoconstitucionalismo, con el dictado por parte de la Corte Suprema de Justicia de la Nación de los precedentes Vizzoti y Aquino en el año 2004, que reivindicaron la primacía operativa de los principios constitucionales y asignaron la calificación del trabajador como sujeto de "preferente" o "especial" tutela constitucional (Ambesi, 2017). Cuatro años más tarde, cuando el alto tribunal emitió la sentencia Asociación Trabajadores del Estado (conocida también como ATE I), en la que declaró la inconstitucionalidad de los recaudos previstos en la Ley 23551 para la postulación y elección de delegados -restringida a los sindicatos con personería gremial-, el sistema jurídico sindical recibió la comunicación como una interpelación a su código cerrado. ${ }^{?}$

A casi veinte años del movimiento inicial, puede decirse que los citados pronunciamientos no fueron los únicos ni los más relevantes en la producción del cambio. Entiéndase bien: lo anterior no significa restarle importancia a la hora de presentarlos como hitos jurisprudenciales en la materia, lo que aquí interesa es verlos desde otro vértice, desde el cual los fallos operaron como inputs más allá de lo expresado en sus argumentos. En otras palabras, importa verlos en el desborde funcional que provocaron en el sistema de la Ley 23551.

Es evidente que la reacción al cambio del entorno no fue concordante con la velocidad impresa a la transformación encarada. Basta ver algunos de los fallos paradigmáticos dictados por la Cámara Nacional de Apelaciones del Trabajo en este período para comprobar que "opinión" y "acción" sindical se fundían

7 Se trata aquí de los Fallos: 327:3677 del 14/09/2004; 327:3753 del 21/09/2004; y 331:2499 del $11 / 11 / 2008$. 
en un solo movimiento comunicativo, impactando en la calificación del despido como discriminatorio. ${ }^{8}$

Dos años después del precedente ATE, la Corte Suprema de Justicia de la Nación emitió el fallo Álvarez c/Cencosud, en el que se estableció la aplicación de la Ley 23592 antidiscriminatoria a las relaciones laborales, validando por mayoría la reinstalación en su puesto de trabajo de quienes habían sido despedidos (en el caso intentaban formalizar la creación de una asociación sindical destinada a la defensa de sus intereses profesionales).

El voto mayoritario dice más por lo que omite del régimen sindical que por lo que afirma. Salvo la referencia al Pacto Federal del Trabajo, aprobado por la Ley 25212, que tipifica y sanciona las decisiones empleadoras que impliquen una discriminación -entre otros, por motivos gremiales-, no hay alusión más cercana a la ley de asociaciones sindicales. Se exhibe, eso sí, un amplio despliegue de instrumentos, jurisprudencia y opiniones calificados del derecho internacional, así como un correlativo detalle de fallos dictados por la Corte Suprema en materia de condiciones de trabajo, pero la sentencia no acude a ningún dispositivo de la Ley 23551, ni siquiera para completar la fundamentación. Esto es así porque se estaba consolidando la estructuración de un sistema basado en la gestión de expectativas generadas en torno a otro código binario: el del respeto al principio de igualdad. La definición se implanta de manera evidente en el considerando 11:

... nada hay de objetable a la aplicación en esta causa de la Ley 23592, que reglamenta directamente un principio constitucional de la magnitud del art. 16 de la Constitución Nacional.

La posición minoritaria, encarnada en la disidencia parcial efectuada por otros tres jueces del Colegiado, apunta al nudo de esta cuestión. En primer lugar, porque además de discrepar en cuanto a la reinstalación que supone la declaración de nulidad del despido discriminatorio, hace una referencia concreta a la ley sindical cuando se mencionan los supuestos en los cuales el ordenamiento legal ha clausurado temporalmente la posibilidad de la extinción del vínculo sin causa para los representantes gremiales (artículos 48/50 de la Ley

8 Cfr., entre otros, Cámara Nacional de Apelaciones del Trabajo, Sala VI, 20/03/2004, Balaguer, Catalina c/Pepsico de Argentina S.R.L.; Sala IX, 31/05/2005, Greppi, Laura c/Telefónica de Argentina S.A.; Sala V, 14/06/2006, Parra Vera, Máxima c/San Timoteo S.A. El Boletín Temático de Jurisprudencia de la Cámara Nacional de Apelaciones del Trabajo, publicado en el año 2012, da buena cuenta de las diferentes opiniones y evaluaciones formuladas en esa época. 
23551, ver considerando 14). En segundo término, porque destaca el propio rasgo funcional de la Ley 23592, al advertir en su considerando 16 que

... en razón de su carácter general y trasversal a todas las ramas del derecho, requiere de una aplicación apropiada que no distorsione el equilibrio de derechos al que responde cada sector del ordenamiento jurídico, sea público o privado.

Visto con los ojos de la actualidad, la turbulencia sistémica provocada por Álvarez aparece de similar o superior magnitud a la de otros fallos de la época. Con la entrada de la Ley 23592 a pleno en la órbita sindical, se inaugura un nuevo período sistémico de diferenciación funcional. El par que puede denominarse "trabajadores con actividad sindical no discriminados/trabajadores con actividad sindical discriminados", derivado de una norma que involucra otros supuestos en juego, ingresa en el ámbito gremial con sus propios códigos para forjar su estructura de reducción de complejidad y canalizar a través de él sus operaciones decisorias. Estas resoluciones, sin perjuicio de disponer el cese y/o nulidad del acto controvertido, pueden adicionar reparaciones por los daños ocasionados de acuerdo a lo previsto en el texto aplicado. La Corte Suprema se ocupó especialmente de advertir sobre el tratamiento que debía dársele al reclamo por daño moral (caso Bichi), como también de ratificar la vigencia de la reinstalación en el empleo provocada por la nulidad del despido discriminatorio (caso Cejas c/Fate).

La solución de un problema conduce a otro, y en esto queda en primer plano el vértice probatorio. La vinculación entre lo que se denuncia como conducta discriminatoria y lo que se acredita no deja de ser un requisito común a todo pleito. Hay que notar que la Corte Suprema revocó, al tiempo de sentar su doctrina en Álvarez y ante la falencia de esta conexión, una sentencia que había admitido la reinstalación de una trabajadora con base en el carácter discriminatorio del despido, señalando en la causa Pellejero que ni del fallo atacado ni de la demanda incoada se explicaban los hechos y circunstancias en los que se habrían puesto de relieve los extremos discriminatorios ni lo elementos arrimados al juicio que favorecían tal ponderación.

Pero el problema seguía abierto y llamaba a ser resuelto, por lo que el máximo tribunal fijó en el año 2011, a través del precedente Pellicori, las pautas procesales para los litigios de esta índole:

... resultará suficiente, para la parte que afirma dicho motivo, con la acreditación de hechos que, prima facie evaluados, resulten idóneos para inducir su 


\begin{abstract}
existencia, caso en el cual corresponderá al demandado a quien se reprocha la comisión del trato impugnado, la prueba de que éste tuvo como causa un motivo objetivo y razonable ajeno a toda discriminación. La evaluación de uno y otro extremo, naturalmente, es cometido propio de los jueces de la causa, a ser cumplido de conformidad con las reglas de la sana crítica [...] La doctrina del Tribunal, por ende, no supone la eximición de prueba a la parte que tilda de discriminatorio un actor pues, de ser esto controvertido, pesa sobre aquella la carga de acreditar los hechos de los que verosímilmente se siga la configuración el motivo debatido. Tampoco implica, de producirse esa convicción, una inversión de la carga probatoria ya que, ciertamente, en este supuesto, al demandado le corresponderá probar el hecho que justifique descartar el prima facie acreditado. (considerando $11^{\circ}$ )
\end{abstract}

Frente a este diagrama, la doctrina anticipó el próximo debate en torno a la discriminación, especialmente con relación a la profundidad de la actividad sindical. Como se pregunta Guibourg (2015), a los fines de habilitar la rotación de la carga probatoria

¿qué clase o intensidad de activismo sindical ha de considerarse suficiente? El representante y el candidato están amparados por la Ley 23551; al parecer, quien hace gestiones sindicales ante el empleador o promueve la constitución de un nuevo sindicato, está incluido en lo que pudiera llamarse 'vulnerabilidad discriminatoria' ¿Qué otras circunstancias implican esa vulnerabilidad? He aquí un continuo de intensidades en el que sería conveniente fijar un límite reconocible. (p. 489)

La nueva dificultad, entonces, radica en el reconocimiento por parte del juzgador de esa profundidad en la discriminación sindical; constituye el modo de arranque que lleva a poner en marcha la operación rotatoria antes indicada. La diferenciación interna del sistema aquí pasa a ser "intenso/no intenso". De allí la idea que sostiene E. Álvarez (2012) consistente en denominar a los indicios requeridos por el precedente Pellicori como "humo de discriminación", sosteniendo con ello que la Corte no se ha apartado de la "... estricta jurisdiccionalidad que presupone la corroboración judicial de la ilicitud” (p. 73).

Ambas reflexiones favorecen el presente estudio, en tanto reflejan otros aspectos del problema de funcionalidad que se postula y se ha encauzado por dotar preeminencia a la ley antidiscriminatoria como sistema idóneo frente al de la ley sindical, de cuyo sendero procesal se ha apropiado. Es que si la intensidad de la actividad gremial pasible de discriminación se reconoce a partir de la constatación de este fumus boni iuris específico, no resulta necesario transitar un 
proceso de pleno debate y prueba para resolver su protección. Sea que se trate de una acción de amparo general, del particular amparo sindical del artículo 47 de la Ley 23551 o de cualquier otro trámite tutelar expedito, el objetivo estaría cumplido.

Así es como ha sucedido muchas veces en la práctica. Ello revela que el sistema de la Ley 23592 montó su estructura y cooptó al mismo tiempo la vía breve contenida en el sistema de la Ley 23551. La interpenetración sistémica condujo a gestionar una expectativa creciente, como es la de resolver estas situaciones derivadas de la libertad sindical que excedieron hace tiempo la mera "opinión" del texto originario de la primera de las normas y el mero "cese" del comportamiento antisindical de la segunda de ellas. A base de sucesivas diferenciaciones funcionales, se ha pergeñado un nuevo sistema.

La hiperfuncionalidad de la Ley 23592 para gestionar los grados de confianza y expectativa en la resolución de controversias basadas en la discriminación sindical para aquellos sujetos no tutelados especialmente por la Ley 23551 puso de manifiesto la necesidad de avanzar en un deslinde de sistemas y mecanismos probatorios para evitar distorsiones, tanto en lo referido al tándem activo subjetivo/objetivo (a quién se protege y cuál es el comportamiento de resguardo) como en lo vinculado al destinatario pasivo de la pretensión, principalmente el empleador, dado que la consecuencia de la nulidad del despido discriminatorio trae consigo el restablecimiento de la condición anterior. La misma hiperfuncionalidad detectada llevó al alto tribunal a dejar sin efecto una medida cautelar de reinstalación con el fundamento de que anticipaba la solución de fondo (caso Laurenzo).

En este sentido, la Corte Suprema de Justicia de la Nación delineó un camino decisorio jurisdiccional con bifurcaciones dedicadas a habilitar y deshabilitar cada uno de los pasos hermenéuticos implicados en la discriminación y su particular subtipo sindical. Desde esta perspectiva, el precedente Varela c/Disco, del año 2018, puede ser considerado como un manual del usuario, elaborado con directrices para acoplar y desacoplar sistemas que son entornos de otros.

Las llaves de este mecanismo se encuentran en el considerando $9^{\circ}$, que se afirma en un razonamiento jurídico-judicial que amerita la siguiente partición.

Validación del estándar probatorio ante el problema intersistémico: para la Corte, lo dicho en Pellicori resulta de plena aplicación a la causa, en la que se discute si un despido ha sido motivado por razones sindicales, en el marco de la Ley 23551, o por razones de opinión gremial conforme la Ley 23592. Por ello, quien alega la existencia de un motivo discriminatorio debe acreditar en 
principio o verosímilmente que se encontraba llevando a cabo una actividad protegida por las normas que invoca.

Primera distinción: para el máximo tribunal, “... no cualquier actividad u opinión en el ámbito laboral es de carácter sindical o gremial [...] quien invoca un despido discriminatorio en los términos de la ley 23.551 debe mostrar verosímilmente que realizaba una actividad sindical específicamente protegida por dicha ley”. El requerimiento parece genérico, pero no lo es. Ya ubica el supuesto en el sistema jurídico sindical y la exigencia que continúa profundiza los límites del campo de acción: "Más aún, el interesado debe acreditar de modo verosímil que estaba ejerciendo una actividad protegida en dicha ley de modo regular. El art. 47 de la referida ley 23.551 así lo exige expresamente”.

Se observa un rescate metodológico de aquel concepto ya analizado en este trabajo. La diferenciación "ejercicio de modo regular/ejercicio de modo irregular" recobra protagonismo y se apela a la textura originaria del amparo sindical para demarcar la geografía tuitiva. La hermenéutica final sobre este aspecto trata de clausurar dicho espacio:

No toda actividad sindical constituye el ejercicio regular de un derecho sindical y, dado el lenguaje utilizado, no puede entenderse que la norma otorgue la protección que concede a quien no ejerce uno de sus derechos sindicales.

Sin embargo, aquí surge otra duda. Si el amparo sindical se concentra en quienes ejercitan "de modo regular" sus derechos sindicales, además de los ya tutelados por su situación (representante gremial, candidato, dirigente), queda otro conjunto de sujetos que también pueden invocar dicho ejercicio regular, apelando a los postulados de libertad sindical contenidos en la propia ley. La salida a esta discusión remite, nuevamente, a una ponderación de la "intensidad" con la que se ejerció el derecho sindical y el contexto en el cual se realizó. En otras palabras, a un discernimiento probatorio por parte del operador judicial.

Segunda distinción: el pronunciamiento se enfoca luego en el sistema antidiscriminatorio. Afirma que "En el caso de la ley 23.592, el interesado debe acreditar de modo verosímil que el tipo de actividad desarrollada cuenta como una opinión gremial a los fines de dicha ley y que la actividad satisface los requisitos más generales del ejercicio de la libertad de expresión”.

Como en el supuesto anterior, se practica una remisión expresa al texto de la ley, intentando fijar el límite en la noción de "opinión", pero anudándola a otro derecho fundamental antes que al ejercicio de los derechos sindicales. 
En este desnivel de relevancias parece más importante lo que el sujeto a tutelar "manifiesta" que lo que "hace" en concreto con su libertad sindical.

La frontera entre ambos comportamientos remite, de nuevo, a cuestiones fácticas.

Tercera distinción: finalmente, este segmento del fallo se expide en relación con la calidad de respuestas que puede brindar el empleador imputado por la discriminación de su despido, una vez acreditada la verosimilitud de la conducta, cuando la decisión extintiva es incausada:

... en la medida en que nuestro régimen constitucional y laboral no ha vedado el supuesto de despido sin causa y, por lo tanto, el empleador puede rescindir el vínculo laboral sin justificación alguna, es suficiente para evitar las consecuencias que las leyes 23551 y 23592 determinen en caso de despidos discriminatorios que el empleador acredite que el trato dispensado al trabajador en cuestión no obedeció al motivo discriminatorio reprochado.

Conforme a lo que se adelantó al inicio, la visión encarada en el presente es de carácter funcional. Desde ese esquema, sorprende que luego de invertir esfuerzos dialécticos en deslindar un sistema de otro, la conclusión sea que ambos resultan idóneos para sustanciar un reclamo por despido discriminatorio y que la reacción del empleador no estaría tanto en la naturaleza y el modo de ejercicio de los derechos, sino en la causalidad del despido. Es más, la fórmula concluye expresando: "Bastará que demuestre que el distracto se dispuso por cualquier otro motivo, de la naturaleza que fuere. La única limitación es que la rescisión no responda a los móviles discriminatorios proscriptos".

Resta el caso del distracto con expresión de la causal resolutiva. Para este supuesto, se emplea un mecanismo similar al anterior con un matiz final:

... Si la desvinculación se ha producido con invocación de causa, es suficiente para el empleador acreditar que dicha causa razonablemente se ha configurado. Por último, sea que se trate de la parte que alega el motivo discriminatorio o de aquella que niega su existencia, para la acreditación de los extremos mencionados y para la evaluación de la prueba deben emplearse los medios habituales.

¿Hay en esta última parte del considerando una disminución de la entidad probatoria que posee el material indiciario? ¿O es solamente una ratificación de las distintas modalidades de prueba que pueden utilizarse para ello?

La suma de estas disquisiciones revela que el objetivo pretendido en Varela no se habría cumplido en su totalidad, y a pesar de haberse transmitido cierta 
idea de cierre jurisprudencial, la aparición tres años más tarde del fallo Fontana indica la vigencia del debate.

A los fines del análisis en curso, este último precedente registra tres posiciones significativas:

La ratificación del estándar fijado en Varela por el voto mayoritario. Luego de reiterar el canon probatorio establecido en Pellicori y Sisnero, la sentencia reivindica la posibilidad que tiene la empleadora para alejarse de la imputación por discriminación gremial del despido, reiterando en el final del considerando $5^{\circ}$ : "Bastará que [el empleador] demuestre que el distracto se dispuso por cualquier motivo, de la naturaleza que fuere. La única limitación es que la rescisión no responda a los móviles discriminatorios proscriptos”. Dicha reivindicación se refleja el considerando $6^{\circ}$ :

\begin{abstract}
... si bien el cuestionamiento a la calidad de activista de la actora no supera el marco de una discrepancia valorativa, asiste razón a la recurrente en cuanto reprocha al fallo de cámara la absoluta falta de tratamiento de su planteo relativo a que la decisión de despedir había obedecido a graves problemas económicos de la empresa, debidamente acreditados en el expediente [...] lo cual configura prima facie una causa seria y objetiva ajena a toda discriminación, en los términos de la doctrina precedentemente reseñada.
\end{abstract}

La variación sobre el estándar fijado en Varela por el voto minoritario concurrente. Mediante una opinión propia, uno de los jueces del alto tribunal (Maqueda) adhiere a la solución anterior, aunque sus fundamentos presentan un matiz distinto. Y es que en el considerando $5^{\circ}$ de este voto se omite, a diferencia de la mayoría, la reiteración de lo dicho en el precedente citado en cuanto a la capacidad extensa que tiene a su disposición el empleador para desvirtuar la motivación atribuida al despido. En palabras sencillas, aquí no hay un "bastará..." y eso es importante para visualizar que la adaptación extensiva de la capacidad argumentativa y probatoria intentada en el año 2018 puede restringirse.

La disidencia que omite el estándar fijado en Varela. El fallo comentado registra una disidencia individual (Rosatti), en la que se aprecian dos elementos reveladores. El primero de ellos es la ausencia de mención del precedente Varela, sobre el que se sustentaron los anteriores votos (el mayoritario en forma total). El segundo aspecto (conectado con el anterior) se refiere a la reivindicación del precedente Pellicori en su versión original, para desestimar la tacha de arbitrariedad de la sentencia inferior, en la parte inicial del segundo párrafo del considerando $4^{\circ}$ : 
... el cuestionamiento a la calidad de actividad de la actora no supera el marco de una discrepancia con la valoración de la prueba realizada por el a quo, y el planteo referente a la omisión de considerar constancias de la causa carece de la debida autosuficiencia, en tanto el recurrente no individualiza cuáles son concretamente los elementos de juicio que lograron demostrar la crisis económica invocada y en qué medida resultaron idóneos para hacer caer los indicios de discriminación que el a quo tuvo en cuenta.

A diferencia de los otros votos, aquí se conecta el obrar gremial de la activista con la aplicación de la regla de rotación de la carga probatoria, a lo que se suman otras circunstancias fácticas de apreciación. ${ }^{9}$

\section{Conclusiones}

Dentro de la extensa producción científica de Luhmann se ha resaltado la necesidad de factorizar o descomponer el continente de un problema -incluyendo sus límites- para obtener una perspectiva que le permita considerar el todo. En cierto sentido, se trata de dividir, de aislar la cuestión de estudio para luego reformular el examen en su integralidad. ${ }^{10}$

Algo de ello se ha intentado aquí. El cercenamiento (cuando ha sido posible) de todo otro material jurídico no imprescindible ha sido de provecho para extraer la cuestión de la diferencia funcional como un módulo impulsor del problema central que se ha presentado.

En el presente, la Ley 23592 resulta, en la visión delineada, el sistema jurídico que mejor absorbe la carga de expectativas y gestiona la incertidumbre de quienes demandan el bloqueo de los comportamientos discriminatorios por motivos sindicales, antes que restringir los planteos dentro del sistema de la Ley 23551 por vía exclusiva del amparo especial.

Las ventajas son numerosas: una amplísima legitimación activa, que alcanza a los propios representantes sindicales y anida a los activistas, militantes y a todo aquel que realice una tarea o formule una manifestación de naturaleza gremial; un conjunto pasivo indeterminado, que alcanza por supuesto a los empleadores; un objeto de protección igualmente extenso, al otorgarse a la acepción "opinión gremial" un contenido tanto del "decir" como del "obrar",

9 “... la actora fue despedida dos veces, la primera al culminar el conflicto gremial de 2013, y la segunda, en octubre de 2014, desvinculación que dio lugar a estas actuaciones".

10 En uno de sus ensayos más conocidos, escrito poco antes de su magnum opus sobre la teoría de los sistemas, Luhmann (2009) inicia su análisis con este comentario epistemológico. 
un comportamiento imputado que puede revestir diversas modalidades (incluso mobbing, acoso, violencia laboral) y un procedimiento flexible, porque la Ley 23592 puede anclarse -según el caso- en las vías del ampro general o del artículo 47 de la Ley 23551, entre otros rituales.

Ante dicho panorama, la ley de asociaciones sindicales adolece de una patente incapacidad. Si bien mucho se ha hablado de la apertura del modelo sindical, lo que se trata de advertir en el presente trabajo es, antes que ello, un agotamiento funcional del sistema para hacerles frente a estas controversias. Los debates y posiciones enarboladas respecto a las inconstitucionalidades de la Ley 23551 (de las que se ha participado) se han enfocado en las dificultades más evidentes del ordenamiento, de cara tanto a las observaciones internacionales como a la evolución judicial que ha seguido. Empero, despejado este panorama, o, mejor dicho, efectuado el trabajo de descomposición, lo que emerge es una situación de déficit funcional por la insuficiente idoneidad de este régimen jurídico para producir operaciones antidiscriminatorias que lleguen a todos quienes se lo requieran.

Para el analista del derecho, la teoría sistémica (en particular la de Luhmann) resulta cruel en determinada medida, más aún si la dinámica adaptativa impone hablar de obsolescencia funcional, ya que la mirada tradicional prefiere posarse en la seguridad jurídica que ofrecen las instituciones para no ingresar en terreno desconocido. El institucionalismo, sin embargo, no es de por sí reprochable para la perspectiva apuntada. Lo que es la sociedad moderna no tolera, y por lo cual busca salidas particularizadas y eficientes, es el inmovilismo normativo totalizador. En esto, la ley antidiscriminatoria se ha ganado su lugar protagónico.

Se habló anteriormente de ventajas funcionales y no pueden soslayarse, a esta altura, algunas desventajas en ese campo. La primera de ellas es que, a tamaña amplitud, se reacciona con una renovada diferenciación. Como ya se explicó, los conceptos de "ejercicio regular" y "derechos reconocidos" vuelven a tomar un puesto de contención a la dispersión originada desde la propia Ley 23592. En segundo lugar, sigue pendiente otra diferenciación en la órbita probatoria: entre lo que se demanda, lo que se responde y lo que se prueba continúa existiendo un vacío conceptual que la teoría de los indicios no alcanza a cubrir con fuerza de clausura. Persiste, entonces, un margen de apreciación en el juez que aún no ha sido delimitado.

Finalmente, resta la construcción de una arquitectura de respuesta al gran interrogante, relativo a la vigencia de la reinstalación como consecuencia de la 
nulidad del despido discriminatorio por opinión gremial. La jurisprudencia ha sido inflexible en este tema, aunque la materia requiere hacer otra diferenciación a partir de casos en los que el remedio previsto puede terminar ocasionando una nueva revictimización, pues no toda reposición en el empleo se mantiene inocua.

Esto significaría, funcionalmente, la realización de una nueva partición interna dentro de la Ley 23592, y quizás la emergencia de un nuevo sistema que atienda esta complejidad.

\section{Bibliografía}

Álvarez, E. (2012). El acto discriminatorio bajo la forma del despido. En Asociación Argentina de Derecho del Trabajo y de la Seguridad Social, Anuario 2011 Despido discriminatorio (Año II, N², pp. 69-96). Rubinzal Culzoni.

Ambesi, L. (2017). Constitución, ley y derecho del trabajo. El sistema jurídico laboral en la teoría y en la práctica. La Ley.

Baxter, H. (2013). Niklas Luhmann's Theory of Autopoietic Legal Systemas. Annual Review of Law and Social Science, 9, 167-184.

Corsi, G., Esposito, E. y Baraldi, C. (2006). GLU. Glosario sobre la teoría social de Niklas Luhmann (Trad. M. Romero Pérez, C. Villalobos). Universidad Iberoamericana.

Guibourg, R. (2015). Vulnerabilidad discriminatoria. Derecho del Trabajo, (3), 487-494.

Fernández Madrid, J. C. (1985). Bases para una ley de organización sindical. Derecho del Trabajo, A, 735.

López, J. (1998). Libertad sindical. En Derecho Colectivo del Trabajo. La Ley.

López, J., Centeno, N. y Fernández Madrid, J. C. (1987). Ley de contrato de trabajo comentada (2a ed.). Ediciones Contabilidad Moderna.

Luhmann N. (1990). Identität - was oder wie? En Soziologische Aufklärung 5: Konstruktivistische Perspektiven. VS Verlag für Sozialwissenschaften.

Luhmann, N. (1998a). Complejidad y modernidad: de la unidad a la diferencia. Trotta.

Luhmann, N. (1998b). Sistema sociales. Lineamientos para una teoría general (2a ed.). Anthropos Editorial/Universidad Iberoamericana/CEJA, Pontificia Universidad Javeriana.

Luhmann, N. (2005). El derecho de la sociedad (2a ed.). Herder/Universidad Iberoamericana.

Luhmann, N. (2007a). Introducción a la teoría de los sistemas. Lecciones publicadas por Javier Torres Nafarrate. Universidad Iberoamericana/Instituto Tecnológico y de Estudios Superiores de Occidente.

Luhmann, N. (2007b). La sociedad de la sociedad (Trad. J. Torres Nafarrate). Herder/Universidad Iberoamericana.

Luhmann, N. (2009). ¿Cómo es posible el orden social? (Trad. P. Morande Court). Herder/ Universidad Iberoamericana. 
Luhmann, N. (2010). Los derechos fundamentales como institución. Aportación a la sociología politica. Universidad Iberoamericana.

Luhmann, N. (2012). El amor. El amor como pasión. Curso dictado durante el semestre de verano de 1969 (Trad. F. Martín y S. Villegas). Prometeo libros.

Luhmann, N. (2019). Contingencia y derecho. La teoría del derecho en un contexto interdisciplinario. Trotta.

Miranda Rebeco, P. (2012). La precomprensión de lo humano en la sociología de Luhmann. Raíces antropológicas del antihumanismo teórico luhmanniano. Ediciones Universidad Alberto Hurtado.

Nafarrate, J. T. (2009). Introducción. En Maturana R. H., La realidad: ¿objetiva o construida? I Fundamentos biológicos de la realidad (2 ed., pp. 3-63). Anthropos/Universidad Iberoamericana/ITESO/Universidad Jesuita de Guadalajara.

Rodríguez Mancini, J. (1988). Cuestiones constitucionales de la nueva ley sindical. Derecho del Trabajo, B, 1213-1227.

Rodríguez Mancini, J. (1992). Acción de tutela por conductas antisindicales. Trabajo y Seguridad Social, 297-302.

Rottleuthner, H. (1989). A purified Sociology of Law: Niklas Luhmann on the Autonomy of the Legal System. Law Eु Society Review, 23(5), 779-798.

Simon, J. C. (2012a). Introducción al derecho colectivo del trabajo. En Simon, J. C. (Dir.), Tratado de Derecho Colectivo del Trabajo (Tomo I, pp. 3-10). La Ley.

Simon, J. C. (Dir.). (2012b). Tratado de Derecho Colectivo del Trabajo (Tomo I). La Ley.

Van der Kerchove, M. y Ost, F. (1988). El sistema juridico entre orden y desorden. Universidad Complutense.

Vázquez Vialard, A. (1989). La estabilidad absoluta del trabajador víctima de una práctica antisindical. Derecho del Trabajo, A, 1-13.

\section{Jurisprudencia citada}

\section{Corte Suprema de Justicia de la Nación}

Álvarez, Maximiliano y otros c/Cencosud S.A. s/acción de amparo, 07/12/2010, Fallos: 333:2306.

Bichi, Luis Ángel y otros c/Centro de Comisarios Navales s/acción de amparo, 15/12/2015.

Cejas, Adrián Enrique c/Fate S.A. s/juicio sumarísimo, 26/03/2013.

Fontana, Edith Fabiana c/Cibie Argentina S.A. s/juicio sumarisimo, 08/04/2021, Fallos: 344:527.

Laurenzo, Juan Manuel c/Unión Platense s/amparo, 04/06/2020, Fallos: 343:341.

Pellejero, María Mabel s/amparo s/apelación, 07/12/2010, Fallos: 333:2296.

Pellicori, Liliana Silvia c/Colegio Público de Abogados de la Capital Federal s/amparo, 15/11/2011, Fallos: 334:1387.

Sisnero, Mirtha Graciela y otros c/Taldelva S.R.L. y otros s/amparo, 20/05/2014, Fallos: 337:611.

Varela, José Gilberto c/Disco S.A. s/amparo sindical, 04/09/2018, Fallos: 341:1106. 
